\title{
Extracellular ATP acts as a damage-associated molecular pattern (DAMP) signal in plants
}

\author{
Kiwamu Tanaka ${ }^{1}$, Jeongmin Choi $^{2}$, Yangrong $\mathrm{Cao}^{2}$ and Gary Stacey ${ }^{2}$ \\ 1 Department of Plant Pathology, Washington State University, Pullman, WA, USA \\ 2 Division of Plant Sciences and Biochemistry, Christopher S. Bond Life Sciences Center, University of Missouri, Columbia, MO, USA
}

\section{Edited by:}

Martin Heil, Centro de Investigación y de Estudios Avanzados del Instituto

Población Nacional - Unidad Irapuato, Mexico

\section{Reviewed by:}

Stanley Roux, The University of Texas at Austin, USA

Stephen Chivasa, Durham University, UK

\section{*Correspondence:}

Kiwamu Tanaka, Department of Plant Pathology, Washington State University, P.O. BOX 646430, Pullman, WA 99164, USA

e-mail: kiwamu.tanaka@wsu.edu
As sessile organisms, plants have evolved effective mechanisms to protect themselves from environmental stresses. Damaged (i.e., wounded) plants recognize a variety of endogenous molecules as danger signals, referred to as damage-associated molecular patterns (DAMPs). ATP is among the molecules that are released by cell damage, and recent evidence suggests that ATP can serve as a DAMP. Although little studied in plants, extracellular ATP is well known for its signaling roles in animals, including acting as a DAMP during the inflammatory response and wound healing. If ATP acts outside the cell, then it is reasonable to expect that it is recognized by a plasma membrane-localized receptor. Recently, DORN1, a lectin receptor kinase, was shown to recognize extracellular ATP in Arabidopsis. DORN1 is the founding member of a new purinoceptor subfamily, P2K (P2 receptor kinase), which is plant-specific. P2K1 (DORN1) is required for ATP-induced cellular responses (e.g., cytosolic $\mathrm{Ca}^{2+}$ elevation, MAPK phosphorylation, and gene expression). Genetic analysis of loss-of-function mutants and overexpression lines showed that P2K1 participates in the plant wound response, consistent with the role of ATP as a DAMP. In this review, we summarize past research on the roles and mechanisms of extracellular ATP signaling in plants, and discuss the direction of future research on extracellular ATP as a DAMP signal.

Keywords: extracellular ATP, DAMPs, immune defense, wound healing, symbiosis and immunity

\section{ENDOGENOUS DANGER SIGNALS, DAMPS IN PLANTS}

Multicellular organisms have assembled complex signaling networks that mediate specific and dynamic responses following various environmental stimuli. Among these are mechanisms that recognize a potentially life-threatening event as a danger signal. Danger signals include exogenous, enemy-derived signal molecules, e.g., pathogen-associated molecular patterns (PAMPs), which are recognized by pattern recognition receptors to activate immune responses. In addition, endogenous molecules and fragments from damaged cells and tissues can also be recognized as danger signals, referred to as damage-associated molecular patterns (DAMPs). Multicellular organisms use DAMPs for damageself recognition to evoke immune inflammatory responses and damage healing independent of but in cooperation with exogenous danger signals (Matzinger, 2007).

Because of their sessile nature, plants are continuously exposed to various stresses caused by changes in the environment and attacks by other organisms, i.e., abiotic and biotic stresses. Therefore, plants require sophisticated surveillance systems to detect a variety of danger signals. Indeed, plants have evolved a large number of receptor kinases (e.g., >600 genes in Arabidopsis), most of which are likely involved in the response to different stresses, based on the observation that many duplication events have occurred in the genes involved in defense responses and disease resistance (Shiu et al., 2004). These plant receptors recognize not only exogenous danger signals such as PAMPs and herbivore-associated molecule patterns (HAMPs) but also endogenous danger signals such as DAMPs. A number of PAMPs have been identified, and their recognition systems and downstream signaling events are well studied and understood (Zipfel, 2014). In contrast, only a few DAMPs have been extensively studied (Table 1) and the details regarding their recognition and signaling mechanisms remain unclear. To date, few receptors have been identified that specifically recognize DAMP signals (Table 1). Further studies are needed to clarify each of their signaling mechanisms.

Extracellular ATP is one of the well studied DAMP signals in both animals and plants. Although ATP is well recognized as a source of high energy phosphate bonds to support cellular metabolism, once ATP is released from cells following cellular damage, it acts as a DAMP signal (Figure 1). ATP is a good choice for such a role since cells contain a high concentration of ATP $(1-10 \mathrm{mM})$, which is highly reactive and involved in more chemical reactions than any other compound except $\mathrm{H}_{2} \mathrm{O}$. In animals, extracellular ATP has been studied for over 60 years. The released ATP is recognized by plasma membrane-localized purinergic receptors ( $\mathrm{P} 2 \mathrm{X}$ and $\mathrm{P} 2 \mathrm{Y}$ ) that involve a wide range of animal physiology (Khakh and Burnstock, 2009). In plants, a number of earlier studies reported that extracellular ATP plays essential roles in plant growth and development (Tanaka et al., 2010a). The recent discovery of the plant P2K1 (DORN1) receptor by Choi et al. (2014) demonstrated that extracellular ATP also serves as a DAMP signal in plants. For example, most ATPresponsive genes were also regulated in response to a wound 
Table 1 | Damage-associated molecular patterns (DAMPs) in plants.

\begin{tabular}{llll}
\hline Type & Molecule/fragment & Representative reference & Receptor \\
\hline Nucleotides & ATP & Jeter etal. (2004) & P2K1/DORN1 Choi etal. (2014) \\
& NAD(P)H & Zhang and Mou (2009) & n.d. \\
& DNA & Wen etal. (2009) & n.d. \\
Saccharides & Sucrose & Heil et al. (2012) & n.d. \\
& Oligogalacturonic acid (OGA) & Reymond etal. (1995) & WAK1 Decreux et al. (2006), Brutus et al. (2010) \\
Volatile organic compounds & Green leaf volatiles & Paré and Tumlinson (1999) & n.d. \\
Peptides & Systemin* & Ryan and Pearce (2003) & SR160 Scheer and Ryan (2002) \\
& Pep914/890** & Yamaguchi et al. (2011) & n.d. \\
& Subtilase peptide (SubPep)** & Pearce et al. (2010) & n.d. \\
& Hydroxyproline-rich glycopeptides & Pearce et al. (2007) & n.d. \\
& Elicitor peptides (Peps) & Huffaker etal. (2006) & PEPR1/2 Yamaguchi etal. (2006, 2010) \\
\hline
\end{tabular}

(*) Solanaceae specific peptide; (**) legume specific peptide; (n.d.) not determined.

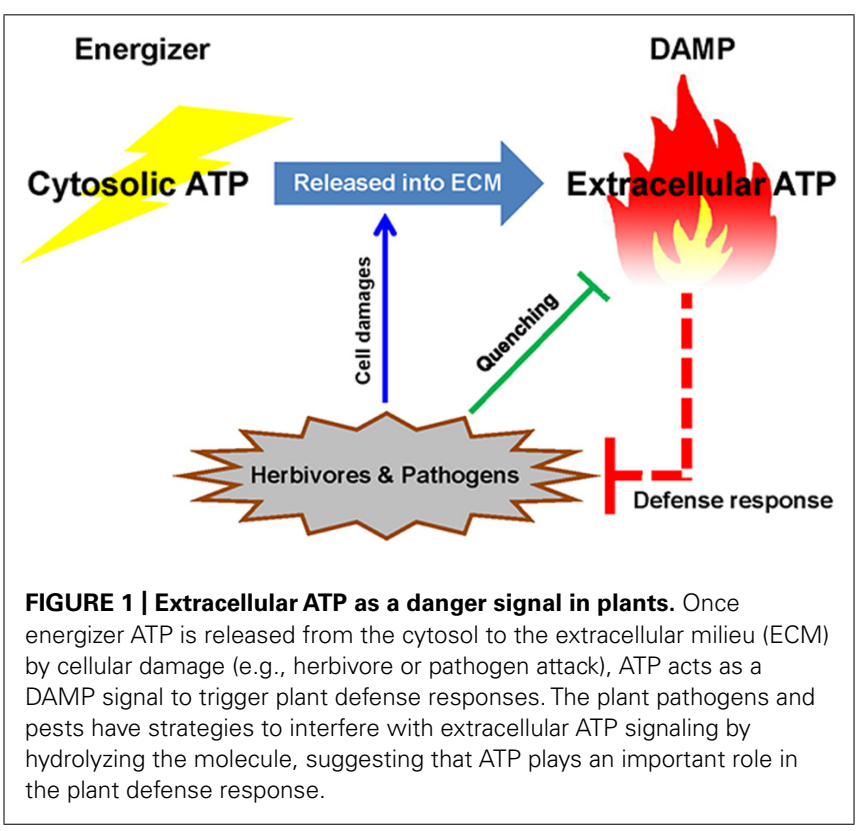

treatment. As would be expected, dorn1 mutant plants showed a reduced transcriptional response to both ATP treatment and wounding. Similarly, overexpression of DORN1 resulted in an elevated response to both ATP and wounding. These data strongly suggest that ATP plays an important role in response to wounding, which is mediated by ATP recognition by the P2K1 (DORN1) receptor.

Detailed analysis of ATP-induced genes by Cao et al. (2014) suggested that extracellular ATP signaling, mediated by P2K1, was also involved in plant responses to a variety of stresses. The suppression of ATP-hydrolyzing enzymes, apyrases (AtAPY1 and AtAPY2), which results in an elevation of extracellular ATP levels, induced the expression of genes involved in stress responses (Lim et al., 2014). Therefore, extracellular ATP likely plays a role as a central danger signaling during a variety of plant stress responses.

\section{ATP IS RELEASED INTO THE EXTRACELLULAR MILIEU AS A DAMP SIGNAL}

The presence of extracellular ATP in plants was detected under various conditions (Table 2), which suggests the existence of mechanisms by which this energy molecule is released into the apoplast. Several mechanisms have been proposed for mediating ATP release (Figure 2). For example, similar to the mechanism of ATP release at animal neuronal synapses, ATP appears to be released at sites of active growth via vesicular exocytosis (Kim et al., 2006). AtPGP1, an ABC transporter, and PM-ANT1, a plasma membranelocalized nucleotide transporter were shown to export intracellular ATP into the extracellular milieu (ECM; Thomas et al., 2000; Rieder and Neuhaus, 2011). However, it remains unclear how these ATP-releasing systems are controlled by environmental stimuli.

Cell breakage is a simple mechanism for ATP release that could be caused by herbivore attack (i.e., wounding) or pathogeninduced cell lysis (i.e., necrosis). This released ATP would be expected to act as a DAMP. Interestingly, $\sim 60 \%$ of the genes induced by ATP treatment are also induced by wounding, $90 \%$ of which responded early to wounding (Choi et al., 2014). In previous studies, the ATP concentrations measured at the wound sites of Arabidopsis leaves (Jeter et al., 2004) and damaged roots (Dark etal., 2011) were $40 \mu \mathrm{M}$ and $80 \mathrm{nM}$, respectively. The effective concentration for ATP signaling at damaged sites may be lower than these measurements, considering that the ATP pool is competitively shared with other ectoenzymes, such as ectophosphatases, ectokinases, and other cell wall enzymes. Given the high affinity of P2K1 for ATP recognition (Kd $\sim 46 \mathrm{nM}$ ), these levels of extracellular ATP would be sufficient to trigger P2K1-mediated ATP signaling. This finding suggests that extracellular ATP released during wounding acts as a DAMP signal and is recognized by the $\mathrm{P} 2 \mathrm{~K} 1$ receptor (Figure 2).

More subtle treatments of plants have also been shown to release sufficient ATP to potentially activate the P2K1 receptor. For example, nanomolar levels of ATP were released 
Table 2 | Release of extracellular ATP during plant growth, development, and stress responses.

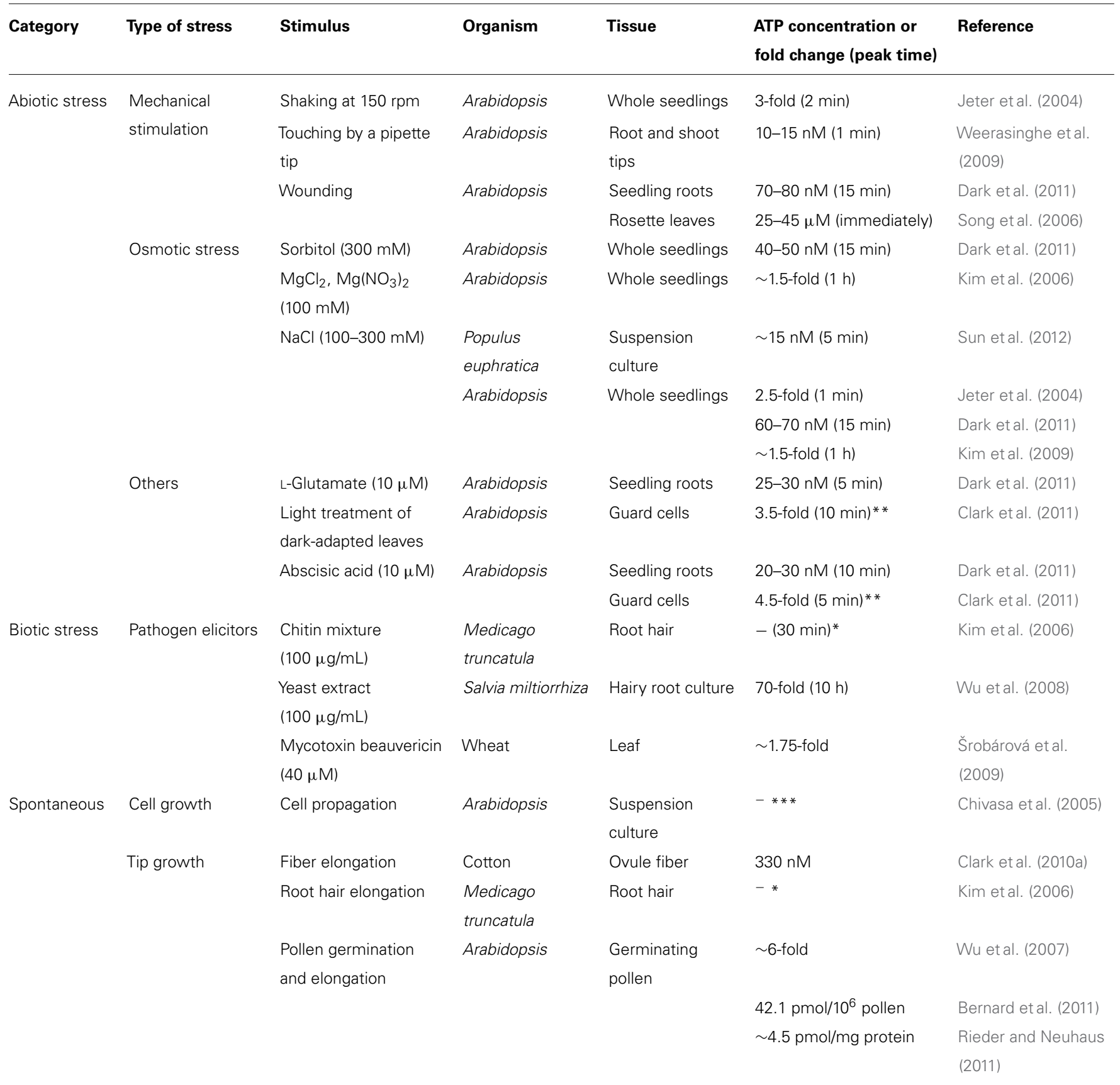

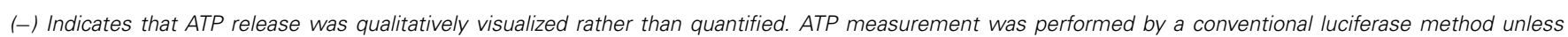

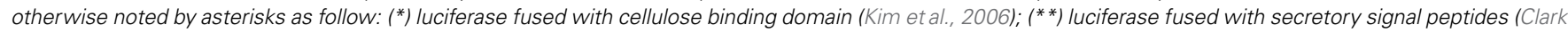
etal., 2011); or (***) thin layer chromatography (Chivasa etal., 2005).

from Arabidopsis roots when a mild touch was applied with a force of $198 \pm 178 \mathrm{mN}$ (Table 2), which is a typical range for plants growing through soil (Weerasinghe et al., 2009). Plants can also experience mechanical stress when infected by microbes. Jayaraman etal. (2014) reported that pathogenic fungi and oomycetes exert mechanical stress by turgor pressure from penetrating pegs and hyphae. Indeed, mechanical stimulation was shown to activate disease resistance
(Benikhlef et al., 2013). Interestingly, pathogen attachment causes nuclear repositioning and cytoplasmic streaming at the contact points on the plant cell (Hardham etal., 2008; Genre et al., 2009; Hardham and Blackman, 2010). These cytoskeletal arrangements are general responses caused by mechanical stimulation (Hardham et al., 2008). Considering that exogenous ATP can also cause cytoplasmic streaming in plant cells (Williamson, 1975), it is conceivable that mechanical stress following pathogen 


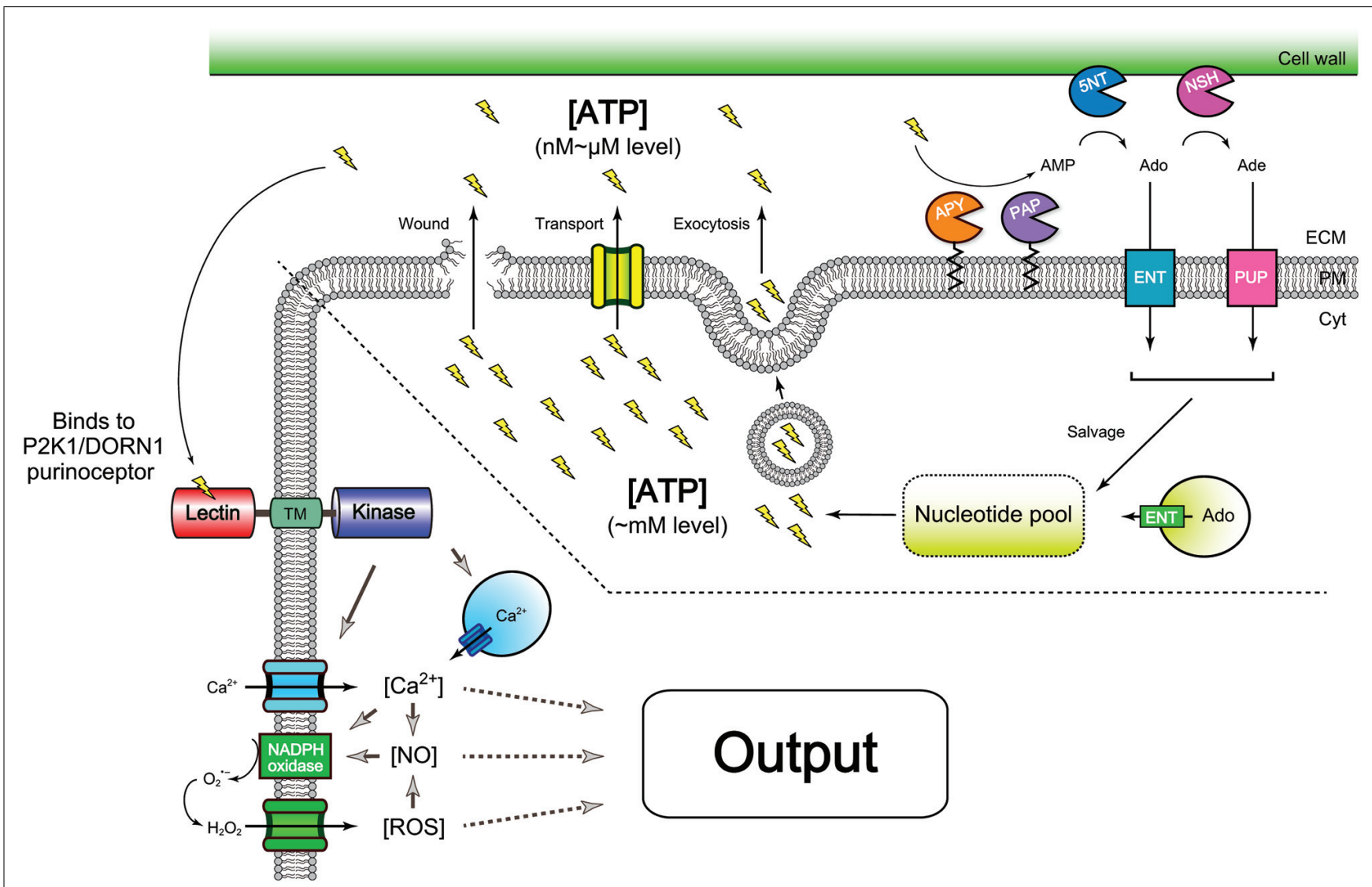

FIGURE 2 | Overview of release, homeostatic control, and signaling of extracellular ATP. Wounding (i.e., cell breakage) is a good example of the release of ATP molecules shown as "lightning" symbols. In addition, a variety of stimuli, e.g., abiotic and biotic stresses can induce ATP release (see Table 1 in detail). These events are suggested to be mediated by an $A B C$ transporter (Thomas et al., 2000), PM-ANT1 transporter (Rieder and Neuhaus, 2011), or exocytotic secretion (Kim et al., 2006). Once cellular ATP (1-10 mM) appears in the apoplast, ATP becomes a signal, i.e., a DAMP signal. The released ATP is then recognized by plasma membrane-localized purinergic receptor, P2K1 (DORN1; left side), which in turn can elevate cytosolic free $\mathrm{Ca}^{2+}$

concentrations, $\left[\mathrm{Ca}^{2+}\right.$ ] (Choi et al., 2014). This causes production of nitric oxide (NO) or ROS (Song et al., 2006; Demidchik et al., 2009). The second messenger trio, $\mathrm{Ca}^{2+}, \mathrm{NO}$, and $\mathrm{ROS}$ activates cellular signaling pathways that eventually lead to induction of various physiological responses, including activation of gene expression. The concentration of extracellular ATP is modulated through the action of ectoapyrases (APY; Lim etal., 2014) and other phosphatases, e.g., purple acid phosphatases (PAP; Liang et al., 2010). After hydrolyses, the end product AMP is further processed to adenosine (Ado) by hypothetical 5'-nucleotidases, 5NT (Riewe etal., 2008) and further to adenine (Ade) by nucleoside hydrolases, NSH, e.g., NSH3 (Jung et al., 2011). Both adenosine and adenine can be reimported into cells by equilibrative nucleoside transporters, ENT, e.g., ENT3 (Bernard et al., 2011) and hypothetical purine permeases (PUP), respectively, and then enter the salvage pathway (Riewe etal., 2008). In other respects, vacuole nucleosides from RNA degradation are exported into cytosolic area by another ENT, e.g., ENT1 (Bernard etal., 2011), that also contributes to cytosolic nucleotide pools. The figure was reconstructed from several schemes in the previous publications (Riewe et al., 2008; Demidchik etal., 2009; Tanaka et al., 2010a; Cao etal., 2014; Möhlmann et al., 2014). Abbreviations: Cyt, cytoplasm; PM, plasma membrane; ECM, extracellular milieu. infection likely stimulates plants to release ATP as a DAMP signal, which eventually evokes cellular responses against the invaders. ATP-induced actin filament formation and cytoskeletal rearrangements are widely observed in animal cells in which ATP modulates inflammation, wound healing and angiogenesis (Kaczmarek etal., 2005). Although such a role for ATP in plants is speculative at this point, it is clear that ATP has the potential to be a missing signal that mediates many of the responses previously attributed solely to mechanical stimulation.

In addition to wounding and mechanical stress, ATP is also released, without visible cell damage, in response to treatment with biotic and abiotic stress agents (Table 2). Abiotic stimuli such as osmotic and salt stress, as well as abscisic acid (a stress-related hormone), and L-glutamate (known as a fast excitatory neurotransmitter in the mammalian nervous system) induce ATP release in plants (Table 2). Biotic stress agents such as pathogen-derived elicitors (i.e., chitin, yeast extract, and mycotoxin beauvericin) also trigger ATP release (Table 2).

Taken together, these findings clearly demonstrate that plants release ATP outside cells in response to various stresses, and the released ATP likely acts as a DAMP signal to trigger plant defenses and environmental stress responses (Figure 2). Further studies are necessary to understand how the ATP-releasing machinery (e.g., transporters and exocytotic vesicles) are regulated by an array of different stimuli. 


\section{ROLE OF EXTRACELLULAR ATP AS A DAMP IMMUNE DEFENSE SYSTEM FOLLOWING WOUNDING AND CELL DAMAGE}

Herbivore feeding, similar to physical wounding, would be expected to passively release high doses of ATP into the extracellular milieu. If this ATP triggers plant defense mechanisms, it would be expected that insects may have adapted to counter this defense. Indeed, some herbivorous caterpillars and whitefly larvae secrete saliva containing apyrases while feeding on plant leaves (Su et al., 2012; Wu et al., 2012). Interestingly, the exogenous application of purified caterpillar apyrase at the wound site suppressed glandular trichome production, which is involved in the defense against herbivores, and the expression of defense-related genes regulated by jasmonic acid and ethylene (Wu et al., 2012). A clear mechanism for this response would be that the salivary apyrases dampen wound-released ATP to restrict the plant defense response. Furthermore, a higher catalytic activity of apyrases was detected in globose insect galls on Calliandra brevipes (Detoni et al., 2012). Similar mechanisms for controlling extracellular ATP concentrations are observed in the interactions between animals and parasitic worms or blood sucking insects (Valenzuela et al., 2001; Da'dara et al., 2014).

Pathogen attacks cause cell damage that allows cytoplasmic ATP to leak into the extracellular space. The reduction of extracellular ATP levels was observed following plant infection by the bacterial pathogen Pseudomonas syringae. Interestingly, this reduction was not observed using a $P$. syringae strain lacking a canonical protein secretion system (Chivasa et al., 2009), suggesting that some effector proteins may contribute to ATP depletion. A recent study showed that adenylate kinases (which phosphorylates AMP using ATP as a phosphate donor) are secreted by Xanthomonas oryzae (Robin et al., 2014). These enzymes could play a role in quenching DAMP-utilized ATP during colonization. Adenylate cyclase were also shown to be important for the virulence of animal pathogens (Markaryan et al., 2001; MunierLehmann etal., 2003). Given that extracellular ATP was shown to be involved in cytolysis, cell adhesion, and growth of various microbes (Roberto Meyer-Fernandes, 2002; Meyer-Fernandes et al., 2004; Li etal., 2011), these pathogenic microbes may be merely protecting themselves from ATP, a very reactive molecule. Correspondingly, a recent report by Long et al. (2014) demonstrated that conidial germination, appressorium formation and pathogenicity of rice blast fungus Magnaporthe oryzae were significantly reduced by pretreatment with nucleotidase-specific inhibitors.

The above results suggest that pathogens and insects directly manipulate extracellular ATP levels to weaken or block plant immunity; thereby promoting colonization of the plant host (Figure 1).

Plants use hormone-mediated pathways, either salicylic acid, jasmonic acid and/or ethylene, to activate defense against pathogens or herbivores (Koornneef and Pieterse, 2008; Mur etal., 2013). The application of ATP induces the expression of genes encoding biosynthetic enzymes for jasmonic acid and ethylene (Jeter et al., 2004; Song et al., 2006). Interestingly, Heil etal. (2012) observed that ATP addition to slightly wounded tissue induced the secretion of extrafloral nectar in the lima bean. The secretion of extrafloral nectar is a jasmonic aciddependent defense response, known to attract ants and other predatory insects (Heil etal., 2001). These results suggest that ATP released following wound damage activates signaling by stress hormones that eventually activates additional defense systems.

It is expected that more than two DAMPs would be present together in the plant apoplastic area at the wound site, where the signals would function together to activate defense response signaling. Oligogalacturonic acid (OGA), another DAMP generated by cell wall degradation (Table 1), is known to trigger cytosolic $\mathrm{Ca}^{2+}$ elevation, reactive oxygen species (ROS) production, and other downstream defense responses (Chandra and Low, 1997). These same responses are also triggered by ATP (Demidchik et al., 2009; Tanaka et al., 2010b). Co-treatment with both OGA and ATP resulted in an enhancement of cytosolic $\mathrm{Ca}^{2+}$ elevation (Jeter et al., 2004). Given that similar defense signaling and gene expression are triggered by both ATP and OGA (Rojo et al., 1999; Jeter et al., 2004), it is likely that these two signals may act synergistically to insure a robust response to wounding.

\section{HEALING AFTER WOUNDING AND CELL DAMAGE}

Wound healing is an essential biological process composed of complex, sequential steps to restore function of damaged cells and surrounding tissues. In animals, this process starts with conserved cellular damage signals (e.g., $\mathrm{Ca}^{2+}$, ROS, and ATP) that diffuse into ambient tissue, surround the wounded area, and initiate immediate cellular events including cell shape changes, actomyosin formation, and immune cell recruitment (Cordeiro and Jacinto, 2013).

Plants lack cellular mobility because of the cell wall and must restore tissue through cellular regeneration at the damaged site. A recent report by Lim etal. (2014) using RNAi silencing of ectoapyrases suggested that accumulated levels of extracellular ATP caused significant changes in the expression of genes regulating wall composition and extensibility. The silenced lines showed changes in wall lignification and decreased methyl ester bonds. These results suggest that extracellular ATP induced by wounding could play an important role in wall reorganization during tissue healing.

The molecular mechanisms of the early stage, plant healing process remain largely unknown, in contrast to those of laterstage wound healing, which has been well studied (Asahina et al., 2002, 2011; Xu et al., 2006; Iwase et al., 2011). Asahina et al. (2011) noted that auxin plays an important role during communication between the repair site and other parts of the plant. Auxin accumulates on the acropetal side of the wound while lower levels are found on the basipetal side. Given that extracellular ATP strongly inhibits polar auxin transport (Tang et al., 2003; Liu et al., 2012), ATP released by wounding could contribute to the auxin distribution at the wound site. Jasmonic acid and ethylene has been postulated to activate specific wound responsive genes that further promote wound healing (Asahina et al., 2011). The addition of ATP induces the expression of genes involved in the biosynthesis of jasmonic acid and ethylene (Choi et al., 2014). Although definitive experimental evidence is lacking, the literature certainly contains clues that extracellular ATP could be 
playing a very important signaling role during the wound healing process.

\section{PLANT-SYMBIONT INTERACTION}

The role of extracellular ATP in symbiosis has been suggested by studies of ectoapyrases, which control the level of extracellular nucleotides. For example, overexpression of soybean ectoapyrase in Lotus japonicus, Medicago truncatula, and soybean resulted in enhanced infection by rhizobia and an increased number of nodules (McAlvin and Stacey, 2005; Tanaka et al., 2011a). In contrast, RNAi silencing and antisense suppression of ectoapyrases in soybean and L. japonicus blocked symbiont infection, resulted in markedly reduced nodulation (Govindarajulu et al., 2009; Roberts et al., 2013). These results are corroborated by earlier studies in which nodule formation on soybean and Dolichos biflorus was inhibited by treatment with specific antibodies against ectoapyrases (Etzler et al., 1999; Day et al., 2000; Kalsi and Etzler, 2000). A recent study by Roberts et al. (2013) also demonstrated that the suppression of ectoapyrase blocked infection by arbuscular mycorrhizal fungi. Taken together, these data suggest that ectoapyrases are essential for both rhizobial and mycorrhizal symbiosis, presumably due to their ability to modulate extracellular ATP levels.

Lipochitooligosaccharides (LCOs), which are known as Nod factors and Myc factors, are key symbiotic signals essential for rhizobial and mycorrhizal symbioses, respectively. Treatment of soybean seedlings with LCO was shown to increase ectoapyrase gene expression (Day et al., 2000). LCO treatment was also shown to result in a re-localization of the apyrase to the root hair tip, which is the site of rhizobial infection (Kalsi and Etzler, 2000). Indeed, LCO treatment was shown to increase the enzymatic activity of the ectoapyrase isolated from $D$. biflorus demonstrating that this ectoapyrase has the ability to bind directly to LCO (Etzler et al., 1999). Therefore, one can hypothesize that, in order to enhance infection, the symbionts use LCO to increase ectoapyrase expression and/or activity; thereby quenching DAMP, extracellular ATP, either released due to mechanical stress during infection (Jayaraman et al., 2014) or as a result of a response to LCO (Tanaka et al., 2011a,b). Studies have shown that ATP, but not ADP, induces ROS production in the root hairs of Medicago truncatula (Kim et al., 2006) and Arabidopsis (Clark et al., 2010b), as well as Arabidopsis epidermal cells (Demidchik et al., 2011). ROS are well-known signals in the plant defense response. Therefore, symbionts may control ectoapyrase activity using LCOs, in which the ATP function as a DAMP is suppressed so that plant defenses are not triggered.

The products of ectoapyrase activity are ADP and/or AMP, which may also have biological activity. For example, ADP was shown to change plasma membrane conductance in root hairs (Lew and Dearnaley, 2000) and induce calcium influx in root epidermal cells (Demidchik et al., 2011). Interestingly, while RNAi silencing of ectoapyrase expression in soybean reduced nodulation, this effect was partially reversed by the addition of exogenous $\mathrm{ADP}$, suggesting a role for extracellular ADP in the nodulation process. Demidchik et al. (2011) used electrophysiological methods to verify the presence of an ADP signaling pathway, independent of ATP signaling, with ionotrophic receptor-like activity at the plasma membrane. P2K1 (DORN1) shows slightly less affinity for ADP over ATP (Choi et al., 2014). It is possible that a second, distinct receptor could exist in plants for ADP, as suggested by Demidchik et al. (2011). Alternatively, it is also possible that ADP recognition by $\mathrm{P} 2 \mathrm{~K} 1$ could activate distinct downstream signaling events, which would also account for the apparent distinct response of ADP vs. ATP. Further research on ADP/ATP signaling pathways, possible additional purinoceptors and P2K1 function should provide answers to these and other questions relevant to nucleotide signaling in plants.

\section{FUTURE PERSPECTIVES OF EXTRACELLULAR ATP AS A DAMP SIGNAL}

The release and response to extracellular ATP is conserved across many taxa, including lower vertebrates, insects, protozoa, and prokaryotes (Burnstock, 1996; Burnstock and Verkhratsky, 2009), indicating that a role for ATP as an extracellular signal is an ancient trait. Therefore, it is not surprising that ATP also plays such a role in plants. However, the $\mathrm{P} 2 \mathrm{~K}$ purinoceptor family is quite distinct from the P2X and P2Y receptors found in animal systems. Hence, although ATP signaling is widely conserved, the means by which plants and animals recognize this signal appears to have evolved independently. However, caution should be used in making such broad conclusions since we are clearly at a very early stage of our understanding of ATP recognition and action in plants. Additional comparative studies are needed to fully elucidate the similarities and differences between the mechanism of action of extracellular ATP in plants and animals.

Plant enemies such as pathogens and insects usually interfere with one or more defense signals to promote colonization and infection. It is now clear that among these mechanisms are strategies for modulating the levels of extracellular ATP. This underlines the important role that ATP plays in general plant stress response (Figure 1).

Although a number of molecular components need to be identified for a complete understanding of extracellular ATP signaling, the recent discovery of the P2K1 (DORN1) purinoceptor (Choi et al., 2014) creates the possibility for further genetic and biochemical studies. As shown in Figure 2, the repertoire of the molecular components identified to date covers a variety of responses induced by extracellular ATP. The following research avenues are of particular interest for further investigation: (1) understanding how these molecular components are controlling extracellular ATP levels following various environmental stimulations and (2) learning the molecular mechanisms of how the ATP signal influences the immune system and subsequent wound healing processes. We propose that extracellular ATP is a key missing signal in many plant stress responses that were previously believed to be due to a direct effect of the stress stimulus itself. Therefore, further knowledge of the role of ATP in plants is crucial to understanding how plants adapt to environmental changes, a crucial question in lieu of a rapidly changing climate.

\section{ACKNOWLEDGMENTS}

This work was supported by grants from the Division of Chemical Sciences, Geosciences, and Biosciences, Office of Basic Energy Sciences of the U.S. Department of Energy, grant no. 
DE-FG02-08ER15309, and the Next-Generation BioGreen 21 Program Systems and Synthetic Agrobiotech Center, Rural Development Administration, Republic of Korea, grant no. PJ009068 (to Gary Stacey), as well as a start-up fund from Department of Plant Pathology, College of Agricultural, Human, and Natural Resource Sciences, Agricultural Research Center, Washington State University (to Kiwamu Tanaka).

\section{REFERENCES}

Asahina, M., Azuma, K., Pitaksaringkarn, W., Yamazaki, T., Mitsuda, N., OhmeTakagi, M., etal. (2011). Spatially selective hormonal control of RAP2.6L and ANAC071 transcription factors involved in tissue reunion in Arabidopsis. Proc. Natl. Acad. Sci. U.S.A. 108, 16128-16132. doi: 10.1073/pnas.1110 443108

Asahina, M., Iwai, H., Kikuchi, A., Yamaguchi, S., Kamiya, Y., Kamada, H., et al. (2002). Gibberellin produced in the cotyledon is required for cell division during tissue reunion in the cortex of cut cucumber and tomato hypocotyls. Plant Physiol. 129, 201-210. doi: 10.1104/pp.010886

Benikhlef, L., L'Haridon, F., Abou-Mansour, E., Serrano, M., Binda, M., Costa, A., et al. (2013). Perception of soft mechanical stress in Arabidopsis leaves activates disease resistance. BMC Plant Biol. 13:133. doi: 10.1186/1471-2229-13-133

Bernard, C., Traub, M., Kunz, H.-H., Hach, S., Trentmann, O., and Mohlmann, T. (2011). Equilibrative nucleoside transporter 1 (ENT1) is critical for pollen germination and vegetative growth in Arabidopsis. J. Exp. Bot. 62, 4627-4637. doi: $10.1093 / \mathrm{jxb} / \mathrm{err} 183$

Brutus, A., Sicilia, F., Macone, A., Cervone, F., and Lorenzo, G. D. (2010). A domain swap approach reveals a role of the plant wall-associated kinase 1 (WAK1) as a receptor of oligogalacturonides. Proc. Natl. Acad. Sci. U.S.A. 107, 9452-9457. doi: 10.1073/pnas.1000675107

Burnstock, G. (1996). Purinoceptors: ontogeny and phylogeny. Drug Dev. Res. 39, 204-242. doi: 10.1002/(SICI)1098-2299(199611/12)39:3/4<204::AIDDDR2>3.0.CO;2-V

Burnstock, G., and Verkhratsky, A. (2009). Evolutionary origins of the purinergic signalling system. Acta Physiol. 195, 415-447. doi: 10.1111/j.17481716.2009.01957

Cao, Y., Tanaka, K., Nguyen, C. T., and Stacey, G. (2014). Extracellular ATP is a central signaling molecule in plant stress responses. Curr. Opin. Plant Biol. 20, 82-87. doi: 10.1016/j.pbi.2014.04.009

Chandra, S., and Low, P. S. (1997). Measurement of $\mathrm{Ca}^{2+}$ fluxes during elicitation of the oxidative burst in aequorin-transformed tobacco cells. J. Biol. Chem. 272, 28274-28280. doi: 10.1074/jbc.272.45.28274

Chivasa, S., Murphy, A. M., Hamilton, J. M., Lindsey, K., Carr, J. P., and Slabas, A. R. (2009). Extracellular ATP is a regulator of pathogen defence in plants. Plant J. 60, 436-448. doi: 10.1111/j.1365-313X.2009.03968.x

Chivasa, S., Ndimba, B. K., Simon, W. J., Lindsey, K., and Slabas, A. R. (2005). Extracellular ATP functions as an endogenous external metabolite regulating plant cell viability. Plant Cell 17, 3019-3034. doi: 10.1105/tpc.105.036806

Choi, J., Tanaka, K., Cao, Y., Qi, Y., Qiu, J., Liang, Y., et al. (2014). Identification of a plant receptor for extracellular ATP. Science 343, 290-294. doi: 10.1126/science.343.6168.290

Clark, G., Fraley, D., Steinebrunner, I., Cervantes, A., Onyirimba, J., Liu, A., et al. (2011). Extracellular nucleotides and apyrases regulate stomatal aperture in Arabidopsis. Plant Physiol. 156, 1740-1753. doi: 10.1104/pp.111.174466

Clark, G., Torres, J., Finlayson, S., Guan, X., Handley, C., Lee, J., et al. (2010a). Apyrase (Nucleoside Triphosphate-Diphosphohydrolase) and extracellular nucleotides regulate cotton fiber elongation in cultured ovules. Plant Physiol. 152, 1073-1083. doi: 10.1104/pp.109.147637

Clark, G., Wu, M., Wat, N., Onyirimba, J., Pham, T., Herz, N., et al. (2010b). Both the stimulation and inhibition of root hair growth induced by extracellular nucleotides in Arabidopsis are mediated by nitric oxide and reactive oxygen species. Plant Mol. Biol. 74, 423-435. doi: 10.1007/s11103-010-9683-7

Cordeiro, J. V., and Jacinto, A. (2013). The role of transcription-independent damage signals in the initiation of epithelial wound healing. Nat. Rev. Mol. Cell Biol. 14, 249-262. doi: 10.1038/nrm3541

Da'dara, A. A., Bhardwaj, R., and Skelly, P. J. (2014). Schistosome apyrase SmATPDase1, but not SmATPDase2, hydrolyses exogenous ATP and ADP. Purinergic Signal. doi: 10.1007/s11302-014-9416-5 [Epub ahead of print].
Dark, A., Demidchik, V., Richards, S. L., Shabala, S., and Davies, J. M. (2011). Release of extracellular purines from plant roots and effect on ion fluxes. Plant Signal. Behav. 6, 1855-1857. doi: 10.4161/psb.6.11.17014

Day, R. B., McAlvin, C. B., Loh, J. T., Denny, R. L., Wood, T. C., Young, N. D., et al. (2000). Differential expression of two soybean apyrases, one of which is an early nodulin. Mol. Plant Microbe Interact. 13, 1053-1070. doi: 10.1094/MPMI.2000.13.10.1053

Decreux, A., Thomas, A., Spies, B., Brasseur, R., Cutsem, P. V., and Messiaen, J. (2006). In vitro characterization of the homogalacturonan-binding domain of the wall-associated kinase WAK1 using site-directed mutagenesis. Phytochemistry 67, 1068-1079. doi: 10.1016/j.phytochem.2006.03.009

Demidchik, V., Shang, Z., Shin, R., Colaco, R., Laohavisit, A., Shabala, S., et al. (2011). Receptor-like activity evoked by extracellular ADP in Arabidopsis root epidermal plasma membrane. Plant Physiol. 156, 1375-1385. doi: 10.1104/pp.111.174722

Demidchik, V., Shang, Z., Shin, R., Thompson, E., Rubio, L., Laohavisit, A., et al. (2009). Plant extracellular ATP signalling by plasma membrane NADPH oxidase and $\mathrm{Ca}^{2+}$ channels. Plant J. 58, 903-913. doi: 10.1111/j.1365-313X.2009.03830.x

Detoni, M. L., Faria-Pinto, P., Quellis, L. R., Rust, N. M., Tavares, L. S., Santos, M. O., et al. (2012). Galls from Calliandra brevipes BENTH (Fabaceae: Mimosoidae): evidence of apyrase activity contribution in a plant - insect interaction. Aust. J. Bot. 60:559. doi: 10.1071/BT12096

Etzler, M. E., Kalsi, G., Ewing, N. N., Roberts, N. J., Day, R. B., and Murphy, J. B. (1999). A nod factor binding lectin with apyrase activity from legume roots. Proc. Natl. Acad. Sci. U.S.A. 96, 5856-5861. doi: 10.1073/pnas.96. 10.5856

Genre, A., Ortu, G., Bertoldo, C., Martino, E., and Bonfante, P. (2009). Biotic and abiotic stimulation of root epidermal cells reveals common and specific responses to Arbuscular mycorrhizal fungi. Plant Physiol. 149, 1424-1434. doi: 10.1104/pp.108.132225

Govindarajulu, M., Kim, S.-Y., Libault, M., Berg, R. H., Tanaka, K., Stacey, G., et al. (2009). GS52 ecto-apyrase plays a critical role during soybean nodulation. Plant Physiol. 149, 994-1004. doi: 10.1104/pp.108.128728

Hardham, A. R., and Blackman, L. M. (2010). Molecular cytology of Phytophthoraplant interactions. Australas. Plant Pathol. 39, 29-35. doi: 10.1071/AP09062

Hardham, A. R., Takemoto, D., and White, R. G. (2008). Rapid and dynamic subcellular reorganization following mechanical stimulation of Arabidopsis epidermal cells mimics responses to fungal and oomycete attack. BMC Plant Biol. 8:63. doi: 10.1186/1471-2229-8-63

Heil, M., Ibarra-Laclette, E., Adame-Álvarez, R. M., Martínez, O., Ramirez-Chávez, E., Molina-Torres, J., et al. (2012). How plants sense wounds: damaged-self recognition is based on plant-derived elicitors and induces octadecanoid signaling PLoS ONE 7:e30537. doi: 10.1371/journal.pone.0030537

Heil, M., Koch, T., Hilpert, A., Fiala, B., Boland, W., and Linsenmair, K. E. (2001). Extrafloral nectar production of the ant-associated plant, Macaranga tanarius, is an induced, indirect, defensive response elicited by jasmonic acid. Proc. Natl. Acad. Sci. U.S.A. 98, 1083-1088. doi: 10.1073/pnas.98.3.1083

Huffaker, A., Pearce, G., and Ryan, C. A. (2006). An endogenous peptide signal in Arabidopsis activates components of the innate immune response. Proc. Natl. Acad. Sci. U.S.A. 103, 10098-10103. doi: 10.1073/pnas. 0603727103

Iwase, A., Mitsuda, N., Koyama, T., Hiratsu, K., Kojima, M., Arai, T., et al. (2011). The AP2/ERF transcription factor WIND1 controls cell dedifferentiation in Arabidopsis. Curr. Biol. 21, 508-514. doi: 10.1016/j.cub.2011.02.020

Jayaraman, D., Gilroy, S., and Ané, J.-M. (2014). Staying in touch: mechanical signals in plant-microbe interactions. Curr. Opin. Plant Biol. 20, 104-109. doi: 10.1016/j.pbi.2014.05.003

Jeter, C. R., Tang, W., Henaff, E., Butterfield, T., and Roux, S. J. (2004). Evidence of a novel cell signaling role for extracellular adenosine triphosphates and diphosphates in Arabidopsis. Plant Cell 16, 2652-2664. doi: 10.1105/tpc.104.023945

Jung, B., Hoffmann, C., and Möhlmann, T. (2011). Arabidopsis nucleoside hydrolases involved in intracellular and extracellular degradation of purines: Arabidopsis nucleoside hydrolase family. Plant J. 65, 703-711. doi: 10.1111/j.1365313X.2010.04455

Kaczmarek, E., Erb, L., Koziak, K., Jarzyna, R., Wink, M. R., Guckelberger, O., et al. (2005). Modulation of endothelial cell migration by extracellular nucleotides. Involvement of focal adhesion kinase and phosphatidylinositol 3-kinase - mediated pathways. Thromb. Haemost. 93, 735-742. doi: 10.1267/THRO05040735 
Kalsi, G., and Etzler, M. E. (2000). Localization of a Nod factor-binding protein in legume roots and factors influencing its distribution and expression. Plant Physiol. 124, 1039-1048. doi: 10.1104/pp.124.3.1039

Khakh, B. S., and Burnstock, G. (2009). The double life of ATP. Sci. Am. 301, 84-92. doi: 10.1038/scientificamerican 1209-84

Kim, S.-H., Yang, S. H., Kim, T.-J., Han, J.-S., and Suh, J.-W. (2009). Hypertonic stress increased extracellular ATP levels and the expression of stress-responsive genes in Arabidopsis thaliana seedlings. Biosci. Biotechnol. Biochem. 73, 1252-1256. doi 10.1271/bbb.80660

Kim, S.-Y., Sivaguru, M., and Stacey, G. (2006). Extracellular ATP in plants. Visualization, localization, and analysis of physiological significance in growth and signaling. Plant Physiol. 142, 984-992. doi: 10.1104/pp.106.085670

Koornneef, A., and Pieterse, C. M. J. (2008). Cross talk in defense signaling. Plant Physiol. 146, 839-844. doi: 10.1104/pp.107.112029

Lew, R. R., and Dearnaley, J. D. (2000). Extracellular nucleotide effects on the electrical properties of growing Arabidopsis thaliana root hairs. Plant Sci. 153, 1-6. doi: 10.1016/S0168-9452(99)00242-3

Liang, C., Tian, J., Lam, H.-M., Lim, B. L., Yan, X., and Liao, H. (2010). Biochemical and molecular characterization of PvPAP3, a novel purple acid phosphatase isolated from common bean enhancing extracellular ATP utilization. Plant Physiol. 152, 854-865. doi: 10.1104/pp.109.147918

Li, M., Lee, S.-K., Yang, S. H., Ko, J. H., Han, J. S., Kim, T.-J., et al. (2011). ATP modulates the growth of specific microbial strains. Curr. Microbiol. 62, 84-89. doi: 10.1007/s00284-010-9677-3

Lim, M. H., Wu, J., Yao, J., Gallardo, I. F., Dugger, J. W., Webb, L. J., et al. (2014) Apyrase suppression raises extracellular ATP levels and induces gene expression and cell wall changes characteristic of stress responses. Plant Physiol. 164, 2054 2067. doi: 10.1104/pp.113.233429

Liu, X., Wu, J., Clark, G., Lundy, S., Lim, M., Arnold, D., et al. (2012). Role for apyrases in polar auxin transport in Arabidopsis. Plant Physiol. 160, 1985-1995. doi: 10.1104/pp.112.202887

Long, B., Li, G.-H., Feng, R.-R., Tao, L., Liu, D.-D., Feng, H.-Q., et al. (2014). NTPDase specific inhibitors suppress rice infection by Magnaporthe oryzae. J. Phytopathol. doi: 10.1111/jph.12267 [Epub ahead of print].

Markaryan, A., Zaborina, O., Punj, V., and Chakrabarty, A. M. (2001). Adenylate kinase as a virulence factor of Pseudomonas aeruginosa. J. Bacteriol. 183, 33453352. doi: 10.1128/JB.183.11.3345-3352.2001

Matzinger, P. (2007). Friendly and dangerous signals: is the tissue in control? Nat. Immunol. 8, 11-13. doi: 10.1038/ni0107-11

McAlvin, C. B., and Stacey, G. (2005). Transgenic expression of the soybean apyrase in Lotus japonicus enhances nodulation. Plant Physiol. 137, 1456-1462. doi: 10.1104/pp.104.055939

Meyer-Fernandes, J. R., Saad-Nehme, J., Peres-Sampaio, C. E., Belmont-Firpo, R., Bisaggio, D. F., Do Couto, L. C., et al. (2004). A Mg-dependent ecto-ATPase is increased in the infective stages of Trypanosoma cruzi. Parasitol. Res. 93, 41-50. doi: 10.1007/s00436-003-1066-1064

Möhlmann, T., Steinebrunner, I., and Neuhaus, E. (2014). "Nucleotides and nucleosides: transport, metabolism, and signaling function of extracellular ATP," in Progress in Botany Progress in Botany, eds U. Lüttge, W. Beyschlag, and J. Cushman (Berlin Heidelberg: Springer), 119-144.

Munier-Lehmann, H., Chenal-Francisque, V., Ionescu, M., Christova, P., Foulon, J., Carniel, E., et al. (2003). Relationship between bacterial virulence and nucleotide metabolism: a mutation in the adenylate kinase gene renders Yersinia pestis avirulent. Biochem. J. 373:515. doi: 10.1042/BJ20030284

Mur, L. A. J., Prats, E., Pierre, S., Hall, M. A., and Hebelstrup, K. H. (2013). Integrating nitric oxide into salicylic acid and jasmonic acid/ethylene plant defense pathways. Front. Plant Sci. 4:215. doi: 10.3389/fpls.2013. 00215

Paré, P. W., and Tumlinson, J. H. (1999). Plant volatiles as a defense against insect herbivores. Plant Physiol. 121, 325-332. doi: 10.1104/pp.121.2.325

Pearce, G., Siems, W. F., Bhattacharya, R., Chen, Y.-C., and Ryan, C. A. (2007). Three hydroxyproline-rich glycopeptides derived from a single Petunia polyprotein precursor activate defensin I, a pathogen defense response gene. J. Biol. Chem. 282, 17777-17784. doi: 10.1074/jbc.M701543200

Pearce, G., Yamaguchi, Y., Barona, G., and Ryan, C. A. (2010). A subtilisinlike protein from soybean contains an embedded, cryptic signal that activates defense-related genes. Proc. Natl. Acad. Sci. U.S.A. 107, 14921-14925. doi $10.1073 /$ pnas. 1007568107
Reymond, P., Grünberger, S., Paul, K., Müller, M., and Farmer, E. E. (1995) Oligogalacturonide defense signals in plants: large fragments interact with the plasma membrane in vitro. Proc. Natl. Acad. Sci. U.S.A. 92, 4145-4149. doi: 10.1073/pnas.92.10.4145

Rieder, B., and Neuhaus, H. E. (2011). Identification of an Arabidopsis plasma membrane-located ATP transporter important for anther development. Plant Cell 23, 1932-1944. doi: 10.1105/tpc.111.084574

Riewe, D., Grosman, L., Fernie, A. R., Zauber, H., Wucke, C., and Geigenberger, P. (2008). A cell wall-bound adenosine nucleosidase is involved in the salvage of extracellular ATP in Solanum tuberosum. Plant Cell Physiol. 49, 1572-1579. doi: $10.1093 / \mathrm{pcp} / \mathrm{pcn} 127$

Roberto Meyer-Fernandes, J. (2002). Ecto-ATPases in protozoa parasites: looking for a function. Parasitol. Int. 51, 299-303. doi: 10.1016/S1383-5769(02)00017-X

Roberts, N. J., Morieri, G., Kalsi, G., Rose, A., Stiller, J., Edwards, A., et al. (2013). Rhizobial and mycorrhizal symbioses in Lotus japonicus require lectin nucleotide phosphohydrolase, which acts upstream of calcium signaling. Plant Physiol. 161, 556-567. doi: 10.1104/pp.112.206110

Robin, G. P., Ortiz, E., Szurek, B., Brizard, J.-P., and Koebnik, R. (2014). Comparative proteomics reveal new HrpX-regulated proteins of Xanthomonas oryzae pv. oryzae. J. Proteomics 97, 256-264. doi: 10.1016/j.jprot.2013.04.010

Rojo, E., León, J., and Sánchez-Serrano, J. J. (1999). Cross-talk between wound signalling pathways determines local versus systemic gene expression in Arabidopsis thaliana. Plant J. 20, 135-142. doi: 10.1046/j.1365-313x.1999.00570.x

Ryan, C. A., and Pearce, G. (2003). Systemins: a functionally defined family of peptide signals that regulate defensive genes in Solanaceae species. Proc. Natl. Acad. Sci. U.S.A. 100, 14577-14580. doi: 10.1073/pnas. 1934788100

Scheer, J. M., and Ryan, C. A. (2002). The systemin receptor SR160 from Lycopersicon peruvianum is a member of the LRR receptor kinase family. Proc. Natl. Acad. Sci. U.S.A. 99, 9585-9590. doi: 10.1073/pnas.132266499

Shiu, S.-H., Karlowski, W. M., Pan, R., Tzeng, Y.-H., Mayer, K. F. X., and Li, W.-H. (2004). Comparative analysis of the receptor-like kinase family in Arabidopsis and rice. Plant Cell 16, 1220-1234. doi: 10.1105/tpc.020834

Song, C. J., Steinebrunner, I., Wang, X., Stout, S. C., and Roux, S. J. (2006). Extracellular ATP induces the accumulation of superoxide via NADPH oxidases in Arabidopsis. Plant Physiol. 140, 1222-1232. doi: 10.1104/pp.105.073072

Šrobárová, A., da Silva, J. A. T., Kogan, G., Ritieni, A., and Santini, A. (2009). Beauvericin decreases cell viability of wheat. Chem. Biodivers. 6, 1208-1215.

Sun, J., Zhang, C.-L., Deng, S.-R., Lu, C.-F., Shen, X., Zhou, X.-Y., et al. (2012). An ATP signalling pathway in plant cells: extracellular ATP triggers programmed cell death in Populus euphratica: eATP signalling in poplar PCD. Plant Cell Environ. 35, 893-916. doi: 10.1111/j.1365-3040.2011.02461.x

Su, Y.-L., Li, J.-M., Li, M., Luan, J.-B., Ye, X.-D., Wang, X.-W., et al. (2012). Transcriptomic analysis of the salivary glands of an invasive whitefly. PLoS ONE 7:e39303. doi: 10.1371/journal.pone.0039303

Tanaka, K., Gilroy, S., Jones, A. M., and Stacey, G. (2010a). Extracellular ATP signaling in plants. Trends Cell Biol. 20, 601-608. doi: 10.1016/j.tcb.2010.07.005

Tanaka, K., Swanson, S. J., Gilroy, S., and Stacey, G. (2010b). Extracellular nucleotides elicit cytosolic free calcium oscillations in Arabidopsis. Plant Physiol. 154, 705-719. doi: 10.1104/pp.110.162503

Tanaka, K., Nguyen, C. T., Libault, M., Cheng, J., and Stacey, G. (2011a). Enzymatic activity of the soybean ecto-apyrase GS52 is essential for stimulation of nodulation. Plant Physiol. 155, 1988-1998. doi: 10.1104/pp.110.170910

Tanaka, K., Nguyen, T. H. N., and Stacey, G. (2011b). Enzymatic role for soybean ecto-apyrase in nodulation. Plant Signal. Behav. 6:1034-1036. doi: 10.4161/psb.6.7.15601

Tang, W., Brady, S. R., Sun, Y., Muday, G. K., and Roux, S. J. (2003). Extracellular ATP inhibits root gravitropism at concentrations that inhibit polar auxin transport Plant Physiol. 131, 147-154. doi: 10.1104/pp.013672

Thomas, C., Rajagopal, A., Windsor, B., Dudler, R., Lloyd, A., and Roux, S. J. (2000). A role for ectophosphatase in xenobiotic resistance. Plant Cell 12, 519-533. doi: 10.1105/tpc.12.4.519

Valenzuela, J. G., Belkaid, Y., Rowton, E., and Ribeiro, J. M. (2001). The salivary apyrase of the blood-sucking sand fly Phlebotomus papatasi belongs to the novel Cimex family of apyrases. J. Exp. Biol. 204, 229-237.

Weerasinghe, R. R., Swanson, S. J., Okada, S. F., Garrett, M. B., Kim, S.-Y., Stacey, G., et al. (2009). Touch induces ATP release in Arabidopsis roots that is modulated by the heterotrimeric G-protein complex. FEBS Lett. 583, 2521-2526. doi: 10.1016/j.febslet.2009.07.007 
Wen, F., White, G. J., VanEtten, H. D., Xiong, Z., and Hawes, M. C. (2009). Extracellular DNA is required for root tip resistance to fungal infection. Plant Physiol. 151, 820-829. doi: 10.1104/pp.109.142067

Williamson, R. E. (1975). Cytoplasmic streaming in Chara: a cell model activated by ATP and inhibited by cytochalasin B. J. Cell Sci. 17, 655-668.

Wu, J., Steinebrunner, I., Sun, Y., Butterfield, T., Torres, J., Arnold, D., et al. (2007). Apyrases (Nucleoside Triphosphate-Diphosphohydrolases) play a key role in growth control in Arabidopsis. Plant Physiol. 144, 961-975. doi: 10.1104/pp.107.097568

Wu, S.-J., Liu, Y.-S., and Wu, J.-Y. (2008). The signaling role of extracellular ATP and its dependence on $\mathrm{Ca}^{2+}$ flux in elicitation of salvia miltiorrhiza hairy root cultures. Plant Cell Physiol. 49, 617-624. doi: 10.1093/pcp/ pcn033

Wu, S., Peiffer, M., Luthe, D. S., and Felton, G. W. (2012). ATP hydrolyzing salivary enzymes of caterpillars suppress plant defenses. PLoS ONE 7:e41947. doi: 10.1371/journal.pone.0041947

Xu, J., Hofhuis, H., Heidstra, R., Sauer, M., Friml, J., and Scheres, B. (2006). A molecular framework for plant regeneration. Science 311, 385-388. doi: 10.1126/science. 1121790

Yamaguchi, Y., Barona, G., Ryan, C. A., and Pearce, G. (2011). GmPep914, an eight-amino acid peptide isolated from soybean leaves, activates defense-related genes. Plant Physiol. 156, 932-942. doi: 10.1104/pp.111. 173096

Yamaguchi, Y., Huffaker, A., Bryan, A. C., Tax, F. E., and Ryan, C. A. (2010). PEPR2 is a second receptor for the Pep1 and Pep2 peptides and contributes to defense responses in Arabidopsis. Plant Cell 22, 508-522. doi: 10.1105/tpc.109. 068874
Yamaguchi, Y., Pearce, G., and Ryan, C. A. (2006). The cell surface leucine-rich repeat receptor for AtPep1, an endogenous peptide elicitor in Arabidopsis, is functional in transgenic tobacco cells. Proc. Natl. Acad. Sci. U.S.A. 103, 10104-10109. doi: 10.1073/pnas.0603729103

Zhang, X., and Mou, Z. (2009). Extracellular pyridine nucleotides induce PR gene expression and disease resistance in Arabidopsis. Plant J. 57, 302-312. doi: 10.1111/j.1365-313X.2008.03687.x

Zipfel, C. (2014). Plant pattern-recognition receptors. Trends Immunol. 35, 345-351. doi: 10.1016/j.it.2014.05.004

Conflict of Interest Statement: The authors declare that the research was conducted in the absence of any commercial or financial relationships that could be construed as a potential conflict of interest.

Received: 11 July 2014; paper pending published: 23 July 2014; accepted: 19 August 2014; published online: 03 September 2014.

Citation: Tanaka K, Choi J, Cao Y and Stacey G (2014) Extracellular ATP acts as a damage-associated molecular pattern (DAMP) signal in plants. Front. Plant Sci. 5:446. doi: $10.3389 / \mathrm{fpls} .2014 .00446$

This article was submitted to Plant-Microbe Interaction, a section of the journal Frontiers in Plant Science.

Copyright (c) 2014 Tanaka, Choi, Cao and Stacey. This is an open-access article distributed under the terms of the Creative Commons Attribution License (CC BY). The use, distribution or reproduction in other forums is permitted, provided the original author(s) or licensor are credited and that the original publication in this journal is cited, in accordance with accepted academic practice. No use, distribution or reproduction is permitted which does not comply with these terms. 